\title{
Precisamos Defender o nosso Sistema Público de Saúde!
}

\section{We need to Defend our Public Health System!}

\author{
Nildo Alves Batista ${ }^{I}[\mathbb{D}$ \\ Sandro Schreiber de Oliveira ${ }^{I I}$ (ID \\ Denise Herdy Afonso ${ }^{\text {III }}$ (D) \\ Eduardo Arquimino Postal ${ }^{I V}$ (I) \\ Eliana Goldfarb Cyrino ${ }^{V}$ (D) \\ André Ferreira de Abreu Júnior ${ }^{V I} \mathbb{D}$ \\ Carlos Eduardo Merss ${ }^{\mathrm{VII}}$
}

No final de outubro deste ano, foi publicado no Diário Oficial da União (DOU) o Decreto no $^{\circ}$ 10.530/2020 que instituiu a "política de fomento ao setor de atenção primária à saúde, para fins de elaboração de estudos de alternativas de parcerias com a iniciativa privada". Pelo documento, a ordenação do processo ficaria a cargo da Secretaria Especial do Programa de Parcerias de Investimentos do Ministério da Economia. Poucos dias depois, a portaria foi revogada pelo governo federal, em uma espécie de recuo aparentemente em virtude da ampla repercussão (negativa) gerada.

É fundamental a compreensão de que esse movimento não é um processo isolado de tentativa de privatização do Sistema Único de Saúde (SUS), mas a exacerbação de um desmantelamento histórico sofrido por ele. É preciso compreender esse movimento com atenção às outras políticas de austeridade que vêm precarizando a saúde e a vida do povo brasileiro.

Na ponta dessa lança da privatização do SUS, está a Emenda Constitucional no 95 , aprovada em 15 de dezembro de 2016, que congela o limite de orçamento das despesas primárias por 20 anos e, naturalmente, fere o núcleo do direito à saúde.

Esse recuo do governo federal não representa, em nenhum aspecto, uma mudança nos projetos ou nas iniciativas que constroem (ou destroem) o SUS, mas uma reação à opinião pública acerca do assunto e uma tentativa de manutenção de popularidade. Além disso, esse suposto recuo estratégico advém, sobretudo, de uma análise da reação dos seus aliados do governo e do mercado internacional.

O momento exige grande atenção e organização, pois já se prometeu um novo projeto, reeditado, para os próximos meses. Provavelmente, seguindo a tendência de todos os movimentos dos últimos anos, não será uma vitória para o SUS.

No momento em que este editorial está sendo redigido, o Brasil já ultrapassa 160 mil mortes pela pandemia da Covid-19, e esse número só não é maior em razão da consolidação (ainda que parcial) do SUS. Vale lembrar que cerca de $70 \%$ da população brasileira tem no SUS sua única forma de acesso ao cuidado e à assistência à saúde. Por isso, torna-se ainda mais preocupante a escolha de alguns líderes brasileiros: a de transformar a atual crise da pandemia em tragédia.

No artigo $3^{\circ}$ de seu Estatuto Social, a Associação Brasileira de Educação Médica (Abem), em 58 anos de atividade em prol do desenvolvimento da educação médica no Brasil, destaca o seu compromisso em valorizar a formação de médicas e médicos capazes de atender às necessidades de saúde da população. Além disso, a Abem menciona um objetivo fundamental: contribuir para o fortalecimento do SUS e para a construção de uma sociedade mais justa e igualitária.

Com base nisso, entendemos que este é momento de reafirmar o nosso compromisso com a saúde pública e a educação de qualidade, e articular nossas ideias, nossas instituições e nossos movimentos na defesa do nosso SUS e, sobretudo, na consolidação do pleno direito à saúde para todo o povo brasileiro.

Pelo SUS e para além dele!

Recebido em 5/11/20

Aceito em 5/11/20

REVISTA BRASILEIRA DE EDUCAÇÃO MÉDICA

44 (4) : e182; 2020

IDiretor Presidente da Associação Brasileira de Educação Médica, Brasília, Distrito Federal, Brasil.

${ }^{\mathrm{II}}$ Diretor Vice-Presidente da Associação Brasileira de Educação Médica, Brasília, Distrito Federal, Brasil.

${ }^{\mathrm{III}}$ Diretora Tesoureira da Associação Brasileira de Educação Médica, Brasília, Distrito Federal, Brasil.

${ }^{\mathrm{IV}}$ Diretor Secretário da Associação Brasileira de Educação Médica, Brasília, Distrito Federal, Brasil.

${ }^{\mathrm{v}}$ Diretora de Inovação da Associação Brasileira de Educação Médica, Brasília, Distrito Federal, Brasil.

${ }^{\mathrm{VI}}$ Diretor Médico Residente da Associação Brasileira de Educação Médica, Brasília, Distrito Federal, Brasil.

${ }^{\mathrm{VII}}$ Diretor Discente da Associação Brasileira de Educação Médica, Brasília, Distrito Federal, Brasil. 


\section{CONTRIBUIÇÃO DOS AUTORES}

Os autores contribuíram igualmente para a elaboração do artigo.

\section{CONFLITO DE INTERESSES}

Os autores declaram não haver conflito de interesses neste editorial.

\section{ENDEREÇO PARA CORRESPONDÊNCIA}

Associação Brasileira de Educação Médica. SCN Quadra 2, Bloco D, salas 1021 e 1023, Asa Norte, Brasília, DF, Brasil. CEP: 70712-903.

E-mail: diretoria@abem-educmed.org.br 